\title{
A profissão de Serviço Social e as condições de trabalho dos assistentes sociais na região de Guarapuava - PR
}

\author{
The profession of social work and working conditions of Social Workers in the region of \\ Guarapuava - PR
}

Angela Maria Moura Costa Prates*

\begin{abstract}
Resumo:
O presente artigo tem o objetivo de discutir as condições de trabalho dos Assistentes Sociais na região de Guarapuava-PR que abrange vinte e um municípios. O tipo de abordagem que se propõe é essencialmente quantitativa. Como procedimento metodológico, utiliza-se a pesquisa bibliográfica e documental, e para a coleta de dados fez-se uso do questionário. Discute-se a categoria trabalho na perspectiva de Karl Marx. Em seguida, refere-se às mudanças ocorridas no universo do mundo do trabalho e as consequências para os Assistentes Sociais e, por fim, apresentam-se os dados da pesquisa realizada para compreender as condições de trabalho desses profissionais. Conclui-se que, apesar da legislação em vigência sobre a gestão do trabalho no Sistema Único de Assistência Social, na região em questão ainda encontramos trabalho precarizado.
\end{abstract}

Palavras-chave: Capitalismo. Trabalho. Metamorfoses. Serviço Social. Precarização.

\begin{abstract}
:
The present article has the objective to discuss the labor conditions of the Social workers in the region of Guarapuava-PR that includes twenty one local authorities. The type of approach that is proposed is the quantitative one, with the complementaridade of the qualitative one. Since proceeding methodological uses the bibliographical and documentary inquiry, and for the collection of data it does use of the questionnaire. The category is discussed I work in the perspective of Karl Marx. Next, tell to him to the changes occurred in the universe of the world of the work and the consequences for the Social workers and, finally, it brings the data of the inquiry carried out to understand the labor conditions of these professionals. It is ended that, in spite of the legislation in validity on the management of the work in the System Only one of Social work, in the region open to question we still find work precarizado.
\end{abstract}

Keywords: Capitalism. Work. Metamorphoses. Social Service. Precarious.

\footnotetext{
* Formada em Serviço Social pela Universidade Estadual do Centro Oeste (UNICENTRO). Pós-Graduada em Formação de Professores para a Docência no Ensino Superior pela Universidade Estadual do Centro Oeste (UNICENTRO). Mestre em Ciências Sociais Aplicadas pela Universidade Estadual de Ponta Grossa (UEPG). Atualmente é doutoranda em Serviço Social pela Universidade Federal de Santa Catarina (UFSC) - 2012/2015. E-mail:ammc0406@yahoo.com.br.
} 


\section{Introdução}

O presente artigo originou-se do Projeto de Pesquisa proposto e coordenado pela autora com o título Os assistentes sociais e o mundo do trabalho na região de Guarapuava/PR na Universidade Estadual do Centro-Oeste (UNICENTRO), desenvolvido durante o período de 2009 a 2010. Teve como objetivo discutir as condições de trabalho dos Assistentes Sociais na região de Guarapuava-PR, que abrange vinte e um municípios. Foi necessário, portanto, compreender a categoria trabalho em Marx e as transformações ocorridas a partir do amadurecimento do sistema capitalista e as consequências disso para o Serviço Social enquanto profissão inserida na divisão social e técnica do trabalho coletivo.

A análise que nos aproxima do objeto em questão está ancorada no método crítico dialético, constitutivo da teoria social de Marx "[...] que fornece os elementos categoriais para debater e analisar a composição da sociedade burguesa de forma crítica e histórica." (BOURGUIGNON, 2001, p. 45). É a partir disso que focalizamos o estudo sobre as relações de trabalho em que os assistentes sociais, sujeitos desta pesquisa, estão inseridos.

Para delimitar os sujeitos participantes da pesquisa foi escolhida a Política de Assistência Social por ser um dos maiores campos de trabalho deste profissional; outro fator foi a facilidade de encontrar profissionais atuando nesta política em todos os municípios de Guarapuava-PR. Para conhecer o número exato de assistentes sociais que trabalham na região e os endereços para correspondência, utilizamos documentos oficiais da Secretaria da Família e Desenvolvimento Social (SFDS). Em 2009, trabalhavam na Política de Assistência Social quarenta e dois profissionais.

O tipo de abordagem que utilizamos é a pesquisa quantitativa na qual se "[...] prevê a mensuração de variáveis preestabelecidas, procurando verificar e explicar sua influência sobre outras variáveis, mediante a análise da freqüência de incidências e de correlações estatísticas. O pesquisador descreve, explica e prediz." (CHIZZOTTI, 1998, p. 52). Para coletar os dados, elaboramos um questionário que continha questões como: formação, campo de atuação, condições de trabalho, tipo de contrato, para qual função foi contratado, a contribuição com o Instituto Nacional do Seguro Social (INSS), carga horária, tempo de atuação e média salarial. Também utilizamos a abordagem qualitativa. Elaboramos apenas uma questão aberta solicitando ao participante uma análise da sua 
condição de trabalho na instituição. Realizamos também uma pesquisa bibliográfica documental (nos documentos oficiais da Secretaria do Estado do Trabalho, Emprego e Promoção Social - SETP) para identificarmos os sujeitos, assim como na legislação que trata da Política de Assistência Social e da profissão de Serviço Social.

\section{A categoria trabalho na perspectiva de Karl Marx}

Segundo Marx (1971), o trabalho é a mediação entre homem e natureza e sua relação fundamental. $O$ trabalho é essencial ao real dialético porque é a força dialética, a verdadeira ação dialética. Por meio dele, o homem se apropria da natureza para satisfazer suas necessidades, pelo trabalho a natureza se humaniza, torna-se algo do homem, entra em sua circulação e fica impregnada do humano. Uma natureza trabalhada é ao mesmo tempo uma natureza tornada humana, inserida no homem, mas também o homem inserido nela, traduzido na matéria, introduzido no ser natural. Depois que o homem toca, por qualquer ação ou gesto, a natureza jamais poderá desligar-se definitivamente dele, não impedirá a infiltração do natural no humano nem o humano no natural, pois

[...] ao construir o mundo objetivo o indivíduo também se constrói. Ao transformar a natureza, os homens também se transformam - pois adquirem sempre novos conhecimentos e habilidades. Esta nova situação (objetiva e subjetiva, bem entendido) faz com que surjam novas necessidades (um machado diferente, por exemplo) e novas possibilidades para atendê-las (o indivíduo possui conhecimentos e habilidades que não possuía anteriormente e, além disso, possui um machado para auxiliá-lo na construção do próximo machado). Estas novas necessidades e novas possibilidades impulsionam o indivíduo a novas prévias ideações, a novos projetos e, em seguida, a novas objetivações. Estas, por sua vez, darão origem a novas situações que farão surgir novas necessidades e possibilidades de objetivação, e assim por diante (LESSA, 1999, p. 22-23).

O trabalho instintivo é próprio dos animais, pois ao ato de agarrar os elementos, triturá-los, digeri-los está trabalhando à sua maneira. Mas, o animal procede por uma necessidade imediata, de acordo com o instinto específico. Ao passo que o homem realiza um trabalho consciente, inteligente e livre. O homem trabalha com músculos, mas também com atenção, memória, consciência, liberdade. E é isso que o diferencia dos animais. Segundo Lessa (2008, p. 18): 
Entre os homens, a transformação da natureza é um processo muito diferente das ações das abelhas e formigas. Em primeiro lugar, porque a ação e seu resultado são sempre projetadas na consciência antes de serem construídas na prática. É essa capacidade de idear (isto é criar idéias) antes de objetivar (isto é, de construir objetiva ou materialmente) que funda, para Marx, a diferença do homem em relação à natureza, a evolução humana.

Seu esforço se desenvolve por meio de cálculos, de organização de meios, por raciocínios e visam fins, metas. O homem satisfaz suas necessidades de maneira mediada e não simplesmente como o animal, por instinto. Falamos em mediação porque o homem é capaz de organizar um processo técnico prolongado de produção, pelo qual consegue os bens de consumo mais variados, segundo as formas mais adequadas.

Marx (1971) lembra que o animal só é capaz de reproduzir a si mesmo, enquanto que o homem reproduz também a natureza. Reproduz a natureza porque a faz passar por formas variadas, mediante intermináveis transformações, às quais se sujeita para seus fins humanos e sociais.

Conforme Albornoz (1994), no trabalho distinguem-se três elementos: a ação, o objeto e os instrumentos. A ação é esforço material e intelectual que o homem desenvolve para produzir. É o dinamismo da pessoa aplicado à natureza. O objeto do trabalho é a natureza sobre a qual se exerce a ação. O objeto que se oferece logo à ação é a terra. Na terra estão os minérios, os vegetais, os animais, as matérias-primas que ocupam a atividade do homem. Os instrumentos são os meios de trabalho.

\footnotetext{
Os meios de produção constituem-se dos objetos de trabalho e dos meios de trabalho. Os meios de trabalho incluem tanto os elementos que são precondições essenciais para o funcionamento do processo de trabalho, embora com ele se relacionem indiretamente (canais, estradas, entre outros), quanto os elementos através dos quais o trabalho se exerce sobre seu objeto, como as ferramentas e as máquinas (COLMÁN; POLA, 2009, p. 2).
}

O trabalho humano prepara e usa uma série de instrumentos e aparelhos para que a atividade seja mais eficiente. É interessante notar que os instrumentos saem da natureza transformada. Nesse sentido, resultam de um trabalho anterior. Mesmo que o instrumento seja rudimentar, já contém armazenado em si algum trabalho. O simples fato 
de só recolher uma pedra ou um ramo implica emprego de trabalho na concepção de Marx.

O instrumento é mais do homem do que da natureza, porque está mais desligado da natureza e é usado mais livremente e independentemente pelo homem. Pelo fato de conter trabalho está mais penetrado de humanidade, de cultura. Portanto, o desenvolvimento do trabalho criador aparece, assim, aos olhos de Marx, como uma condição necessária para que o homem seja cada vez mais livre e mais dono de si próprio.

Contudo, Marx (1971) verificou que a partir do desenvolvimento do sistema capitalista de produção, o trabalho assumiu características diferentes das anteriores, em que os homens que produzem os bens materiais, alguns indispensáveis à sua própria existência, não se realizam como seres humanos em suas atividades. Na realidade, o trabalho exteriorizou-se sob a forma de mercadoria, que, conforme Marx é "[...] a riqueza das sociedades onde se rege a produção capitalista [...]." (MARX, 1971, p. 41).

No sistema capitalista de produção, nem sempre o trabalho é a interação do homem com a natureza.

O desenvolvimento do modo produção especificamente capitalista exige, como condição prévia, a separação entre o trabalho e os meios de produção, de forma que o proprietário do trabalho, ou para ser mais exato, da força de trabalho, se veja obrigado a vendê-la ao proprietário dos meios de produção em troca de um salário (COLMÁN; POLA, 2009, p. 3).

Segundo Colmán e Pola (2009), quando pensamos na questão trabalho nos dias atuais é preciso considerar de que tipo de organização social está se falando. Trata-se da sociedade capitalista, na qual diminui o trabalho sob a forma de interação direta do trabalhador com o objeto sendo substituído pelo processo industrial. Ao mesmo tempo a caraterística predominante sob a qual ocorre o trabalho é a venda da mercadoria força de trabalho ao capitalista. "A força de trabalho comprada será incorporada ao capital no processo da produção, valorizando o capital inicial, ou seja, produzindo mais-valia" (COLMÁN; POLA, 2009, p. 3). É a mais-valia o motor que impulsiona a produção capitalista. Se não for para produzir mais valia, o trabalho não se realiza, permanece como potencia mas não se transforma em ato. "Todo o interesse do capital está concentrado nela. Por isso, no modo de produção capitalista, só é produtivo o trabalho 
assalariado que produz mais-valia" (COLMÁN; POLA, 2009, p. 3). A força de trabalho é vendida pelos trabalhadores livres, ou seja, que possuem força de trabalho ${ }^{1}$. Por outro lado, é, também, a única mercadoria que ao ser vendida o dono só recebe após o seu uso. O trabalhador produz o seu pagamento e só depois de produzi-lo é que o receberá. No caso da força de trabalho, o trabalhador só recebe pela sua venda após um mês de trabalho. Assim, no sistema capitalista o que ocorrem são relações entre mercadorias, pois, a força de trabalho do homem tornou-se mercadoria, e só importa pelo seu valor de uso para o capitalista.

A mercadoria é a unidade de valor de uso e valor. Se uma coisa não tem utilidade, tampouco será fonte de valor o tempo de trabalho gasto em produzila. Nesse sentido, pode se dizer que a condição para uma mercadoria ter valor é que tenha alguma utilidade, e há coisas que só manifestam sua utilidade na prestação direta, como no caso dos serviços (COLMÁN; POLA, 2009, p. 13).

Quando o homem encontra-se com as adversidades da vida, seja pela idade, seja pelo desgaste da saúde ou por incapacidade, talvez gerada por consequência do próprio trabalho, ele é descartado como uma mercadoria que perdeu o valor. O empregador busca outro trabalhador, que faz parte do Exército Industrial de Reserva, e que está com a força de trabalho apta e contrata-o.

Com o desenvolvimento do sistema capitalista, o trabalhador perde o papel de protagonista na sua relação com a natureza (COLMÁN; POLA, 2009). Sua função continua sendo a de criar as condições materiais de existência, sua, mas principalmente da classe burguesa, a partir do trabalho, e com isso produzir riquezas, só que não tem acesso a tudo o que produz, mas apenas a uma pequena parte ínfima que mal dá para a sua precária subsistência. O homem por meio do trabalho é quem produz toda a riqueza existente, porém quem vai tomá-la são os donos dos meios de produção, ou seja, a classe burguesa. Não importa quanto o trabalhador produza, o certo é que ele receberá apenas o salário que foi proposto pelo seu empregador. Com uma pequena parte do tempo de

\footnotetext{
${ }^{1} \mathrm{O}$ trabalhador só possui sua força de trabalho quando esta não está vendida a nenhum empregador, ou seja, se ele está desempregado. Na medida em que o trabalhador estiver empregado, não é dono de sua força de trabalho, pois o dono é aquele que a comprou.
} 
seu trabalho, ele paga o seu salário. O restante, ele produz o excedente que Marx chamou de mais-valia. ${ }^{2}$

No sistema capitalista, o trabalhador vive a dimensão da alienação no trabalho, onde ele não participa de todo o processo de sua criação, e muitas vezes não conhece o produto final. Essa relação acontece também com a venda da força de trabalho do assistente social, seja no espaço público ou privado.

No decorrer dos séculos, a concepção de trabalho sofre modificações, pois a sociedade passou por vários modos de produção, sendo que, em todos os modos caraterizados pela divisão da sociedade em classes sociais, verificava-se a exploração do homem pelo homem. ${ }^{3}$ Lessa $(2008$, p. 79$)$ também fala da evolução das sociedades e da exploração do homem pelo homem.

\begin{abstract}
A evolução das sociedades e dos indivíduos passou por várias etapas históricas, demarcadas pela sucessão dos modos de produção (sociedade primitiva, modo de produção asiático, escravismo, feudalismo e capitalismo). No interior de cada uma dessas etapas históricas, se desdobrou uma determinada relação do indivíduo com a sociedade.
\end{abstract}

Para Tavares (2009) existe uma diferença entre a exploração desenvolvida no sistema escravista e feudal, e no sistema capitalista. Nas primeiras formas o patrão era o dono do homem, e na última e atual o patrão é o dono apenas da força de trabalho. A lógica, sendo a lógica do capital, é que o homem é livre para vender sua força de trabalho a quem lhe aprouver. Mas, sabe que essa liberdade é ilusão uma vez que quem detém o comando disso são os donos dos meios de produção. A partir do capitalismo, a força de trabalho humana é mercadoria e passa a ser comprada e utilizada como bem entende o mercado e sua ânsia de lucro. Nesse modo de produção, o trabalhador tem uma falsa ideia de liberdade, enquanto dono de sua força de trabalho, que a torna mercadoria para vendê-la, e o seu valor é determinado como o de qualquer outra mercadoria: pelo tempo socialmente necessário para produzi-lo.

\footnotetext{
${ }^{2}$ Marx distingue dois tipos de mais-valia: ABSOLUTA = a que se obtém pelo prolongamento da jornada de trabalho ou intensificação do ritmo de produção e a RELATIVA = que se obtém reduzindo o valor da força de trabalho (MARX, 1971).

3 "O modo como, mundialmente, se organiza a produção traduz uma longa história de exploração do homem pelo homem, cujas relações sociais são determinadas pelo escravismo, pelo feudalismo e, contemporaneamente, pelo capitalismo." (TAVARES, 2009, p. 240).
} 
A liquidação das formas pré-capitalistas de produção foi acelerada pela expansão da indústria, ou seja, o uso da maquinaria, aumentando com isso o trabalho assalariado. (MARX, 1971). Este contexto é discutido por Antunes (2000) quando fala das metamorfoses do mundo do trabalho, ou seja, das mudanças que ocorreram pelo desenvolvimento do capitalismo. Estas transformações colocaram o trabalhador numa situação contraditória, pois anteriormente ele era parte fundamental para o trabalho, hoje as máquinas o substituem. O criador da máquina, o homem, é substituído por ela. Pois bem, quanto mais os instrumentos de trabalho são qualificados pelo avanço tecnológico, mais o trabalhador fica em segundo plano, restando-lhe apenas competir com os outros para garantir um lugar no mercado. O empregador não tem a preocupação com esse trabalhador, uma vez que pode escolher um deles na fila de desempregados, que esperam desesperadamente por uma vaga.

\footnotetext{
O capitalismo transformou a vida cotidiana em mera luta pela riqueza. Os indivíduos passaram a considerar todos os outros como adversários e a sociedade se converteu na arena em que essa luta se desenvolve. As relações econômicas de mercado são expressões nítidas dessa nova relação entre os indivíduos e a totalidade social. Todos são inimigos de todos [...] (LESSA, 2008, p. 81).
}

Com tudo isso, o mercado de trabalho torna-se exigente demais para aqueles que nele pretende permanecer. Neste contexto, o trabalhador vive uma constante tensão para dar conta de acompanhar o acelerado processo de inovações tecnológicas e, consequentemente, de exigências. Dele é exigida maior qualificação sem, no entanto, garantir-lhe um trabalho com direitos assegurados e melhores salários. Trabalhadores estão sendo constantemente expostos a condições de informalidade que são, na realidade, situações precárias, parciais e temporárias (ANTUNES, 2000). Isso é chamado pelo autor de superproletarização da classe trabalhadora. Esta situação ganhou espaço a partir da expansão capitalista pela intensificação da exploração da força de trabalho física e intelectual. É neste contexto que se discute, a seguir, a inserção do Serviço Social no mundo do trabalho contemporâneo como uma profissão que desenvolve um tipo de trabalho intelectual.

Com a modernização capitalista cresce a precarização do trabalho por meio da informalidade, exercício de atividades de forma insalubre, penosa, em condições 
terceirizadas e baixa remuneração (ANTUNES, 2000). E, além disso, o desemprego e o subemprego trazem para o trabalhador a instabilidade cotidiana, agravando a sua condição de existência tanto individual quanto familiar. Nesse sentido, as conjunturas de rápidas e intensas transformações societárias são o solo fértil para alterações profissionais, tanto no que se refere às novas profissões como no redimensionamento das já consolidadas (NETTO, 1996). E, de maneira significativa, no âmbito do trabalho "[...] muitas foram as modificações trazidas pelo presente tempo histórico [...]." (SOUZA; AZEVEDO, 2004, p. 49).

\section{Os assistentes sociais e o universo do mundo do trabalho}

O Serviço Social não é uma profissão considerada como trabalho desde a sua origem. Essa concepção foi assimilada a partir da década de 1980, quando passa a ser considerado como "[...] uma especialização do trabalho, uma profissão particular inscrita na divisão social e técnica do trabalho coletivo da sociedade." (IAMAMOTO, 2005, p. 22). As mudanças na profissão acontecem pelo impulso das mudanças no contexto mundial.

\footnotetext{
A década de 1980 presenciou nos países de capitalismo avançado profundas transformações no mundo do trabalho, nas suas formas de inserção na estrutura produtiva, nas formas de representação sindical e política. Foram tão intensas as modificações, que se pode mesmo afirmar que a classe-que-vive-dotrabalho sofreu a mais aguda crise deste século, que atingiu não só a sua materialidade, mas teve profundas repercussões na sua subjetividade e, no íntimo inter-relacionamento destes níveis, afetou a sua forma de ser (ANTUNES, 2000, p. 23).
}

Segundo Antunes (2000), a partir daquele momento surgiram novos e diversificados processos de trabalho requerendo do trabalhador novas habilidades, mais capacitação e disponibilidade para assumir diversas funções. A profissão de Serviço Social não está deslocada deste contexto, pois as produções de conhecimento ${ }^{4}$ na área começam a mostrar a necessidade de abordar o Serviço Social como trabalho e isso "[...] supõe apreender a chamada 'prática profissional' profundamente condicionada pelas relações entre Estado e Sociedade Civil, ou seja, pelas relações entre as classes na sociedade [...]" (IAMAMOTO, 2005, p. 23). Esta relação entre Estado e Sociedade Civil foi

\footnotetext{
${ }^{4}$ lamamoto (2005) e lamamoto e Carvalho (1982).
} 
determinante para a constituição e institucionalização do Serviço Social como profissão, pois ele surge no momento que o Estado passa a administrar o conflito de classes, ou ainda, a relação capital e trabalho. Destarte, de acordo com esta autora, a atuação profissional "[...] responde tanto as demandas do capital como do trabalho e só pode fortalecer um ou outro pela mediação do seu oposto [...]" (IAMAMOTO, 2005, p. 75).

O Serviço Social é uma profissão tida como liberal e regulamentada pela Lei no 8.662 de 1993 (CONSELHO FEDERAL DE SERVIÇO SOCIAL, 1993a). Porém, para exercer sua atividade profissional o assistente social precisa vender sua força de trabalho para entidades empregadoras, tanto do setor público quanto privado, inserindo-se numa relação de compra e venda dessa mercadoria particular, participando como trabalhador assalariado da produção e/ou reprodução da riqueza social. Para Silva e Silva (2007, p. 24), existe uma contradição no fato dos Assistentes Sociais "[...] receberem um mandato das classes dominantes para atuarem junto à classe trabalhadora [...]", instituindo uma separação entre os contratantes e os demandantes dos serviços. Segundo a autora é contraditório o fato de receber mandados do empregador, e ter a função ética de responder às demandas dos trabalhadores, as quais nem sempre estão em consonância com as demandas da instituição empregadora. Essa expansão do trabalho assalariado também foi significativa na década de 1980 quando:

[...] efetivou-se uma expressiva expansão do trabalho assalariado, a partir da enorme ampliação no setor de serviços; verificou-se uma significativa heterogeneização do trabalho, expressa também através da crescente incorporação do contingente feminino no mundo operário, vivencia-se também uma subproletarização intensificada, presente na expansão do trabalho parcial temporário, precário, subcontratado “terceirizado" [...] (ANTUNES, 2000, p. 49).

O Serviço Social também foi afetado pelas modificações, porém, com mais intensidade na década de 1990, quando implantadas algumas políticas sociais no Brasil, as quais abriram mais espaços ocupacionais para o Serviço Social. Essas modificações foram sentidas por todas as profissões, não sendo diferente para o Serviço Social, pois as transformações societárias “[...] ao metamorfosear a produção e a reprodução da sociedade, atingem diretamente a divisão sociotécnica do trabalho, envolvendo modificações em todos os seus níveis [...]" (NETTO, 1996, p. 88-89). E ao atingir a divisão sociotécnica do trabalho, exigiu do Serviço Social novas estratégias para enfrentar o 
mercado de trabalho, e, o mais importante, exigiu novas mediações que pudessem dar conta das demandas sociais impostas pelas mudanças na produção e reprodução do capital.

Nesse sentido, lamamoto (2005) afirma que o objeto de trabalho e a matéria-prima do assistente social é a questão social em suas múltiplas expressões ${ }^{5}$. A partir dessa perspectiva, o Serviço Social é considerado trabalho pela autora, pois possui objeto, instrumentos, meios de produção e força de trabalho. Logo, se é considerado trabalho, então ele desenvolve processos de trabalho. No entanto, vale ressaltar que o assistente social não utiliza um, mas diversos processos de trabalho e deixa como produto deste a reprodução da força de trabalho; a obtenção de metas de produtividade; a rentabilidade das empresas; a viabilização de direitos e a prestação de serviços públicos. Por outro lado, o assistente social, como todos os trabalhadores, não detém todos os meios para efetivação de seu trabalho, dependendo também da organização da instituição empregadora.

\begin{abstract}
Ainda que dispondo de relativa autonomia na efetivação de seu trabalho, o assistente social depende, na organização da atividade, do Estado, da empresa, entidades não-governamentais que viabilizam aos usuários o acesso a seus serviços, forneçam meios e recursos para sua realização, estabelecem prioridades a serem cumpridas, interferem na definição de papéis, e funções que compõem o cotidiano do trabalho institucional. Ora, se assim é, a instituição não é um condicionante a mais do trabalho do assistente social. Ela organiza o trabalho do qual ele participa (IAMAMOTO, 2005 p. 63, grifo nosso).
\end{abstract}

Isso implica a tomada de decisões deste profissional, uma vez que precisa negociar as condições materiais para a realização de seu trabalho. Muitas vezes o profissional depara-se com a falta de recursos físicos e materiais para a materialização de sua ação profissional. Faleiros (2009) afirma que nas instituições empregadoras de assistentes sociais podemos encontrar disputa de projetos antagônicos. A instituição pode ter um tipo de projeto e o profissional outro diferente, o que leva ao conflito. Afirma ainda que é perigoso quando o projeto do Serviço Social não entra em conflito algum na instituição, pois pode significar que a profissão não tem nada a questionar. Dissemos PODE, pois uma instituição também pode, eventualmente, ter um projeto de atuação não conflitante com

\footnotetext{
${ }^{5}$ Quanto ao objeto e quanto ao Serviço Social ser ou não ser trabalho existem controvérsias, mas como não é o foco deste trabalho, não iremos nos deter nelas.
} 
os trabalhadores. Seja como for, é necessário que o projeto profissional esteja claramente delineado na instituição para que os usuários e a própria instituição saibam qual é a função social da profissão. Neste sentido, o assistente social tem uma relativa autonomia em suas ações, pois enquanto trabalha com políticas públicas, muitas vezes precisa exercer sua profissão de acordo com as normas da instituição com quem mantém vínculo empregatício, pois "[...] a instituição não é um condicionante a mais do trabalho do assistente social. Ela organiza o trabalho do qual ele participa" (IAMAMOTO, 2005, p. 63). Isso não significa, sobremaneira, que o assistente social não tem nenhuma autonomia. As condições materiais de trabalho, recursos etc. são oferecidas pela instituição, mas o profissional é livre para também conquistar espaços dentro dela e passar a participar de todo o processo de organização de seu trabalho. Assim como, quando o profissional está com o usuário, somente ele (em conjunto com o usuário) tem a autonomia para decidir sua intervenção, e, portanto, nesse espaço ele é autônomo. Por isso, lamamoto (2005) entende que o profissional tem relativa autonomia, pois nem tudo depende dele, mas tem questões que dependem do seu empregador. É neste sentido que o profissional vive as contradições de uma sociedade de classes em relações de exploração do trabalho.

\section{As condições de trabalho dos assistentes sociais na região de Guarapuava-PR}

Aqui iremos discutir as condições de trabalho dos assistentes sociais que trabalhavam na Política de Assistência Social entre 2009 e 2010 na região de GuarapuavaPR que abrangia vinte e um municípios. Escolhemos essa política pública em especial porque ela está sendo operacionalizada em todos os municípios, e, portanto, possibilita uma visão mais abrangente do assunto. A tematização das condições de trabalho dos profissionais que atuam na Política de Assistência Social pelo próprio Estado é fato recente. Esta novidade pode ser verificada pela Norma Operacional Básica de Recursos Humanos (NOB/SUAS-RH), que, diante da precarização do trabalho indicaria que o Estado inicia uma Política de Recursos Humanos para seu enfrentamento, haja vista que isso influencia diretamente a qualidade da prestação de serviços, que é sua finalidade. A precariedade do trabalho não aparece apenas nas empresas privadas, mas também no Estado por meio de contratos temporários, testes seletivos, prestação de serviços e 
outras formas (como processos licitatórios ${ }^{6}$ ) que são instáveis e com baixa remuneração. Consideramos a licitação a pior das formas de se contratarem profissionais, pois estes vencem a licitação quando vendem sua força de trabalho pelo menor preço. Por outro lado, não raras vezes, sempre que ocorre a troca de gestor (prefeito) nas prefeituras, muda-se, quase que completamente, o quadro de funcionários, uma vez que cada gestão tem seus cabos eleitorais para empregar.

De acordo com a NOB/RH-SUAS, no contexto da Política de Assistência Social, estão previstas mudanças fundamentais que contribuem com o enfrentamento da precarização do trabalho, pois "[...] o SUAS vem se consolidando, e a gestão do trabalho na Assistência Social carece de uma atenção maior devido a sua importância para a consolidação do sistema" (PARANÁ, 2006, p. 17). Então, a implementação do SUAS, além de outros fatores, também depende dos trabalhadores que vão operá-lo. E para a Secretaria Nacional de Assistência Social, esse documento seria uma das primeiras iniciativas para a consolidação de uma política na área da gestão do trabalho, pois:

\begin{abstract}
Trata-se de um primeiro esforço nesta área, objetivando delinear os principais pontos da gestão pública do trabalho e propor mecanismos reguladores da relação entre gestores e trabalhadores e os prestadores de serviços socioassistenciais, o que não esgota as possibilidades de aprimoramento desta Norma (PARANÁ, 2006, p. 17).
\end{abstract}

Destarte, a gestão do trabalho na área da Assistência Social, no que tange ao processo de consolidação do SUAS, requer diretrizes para nortear as ações com relação à gestão do trabalho, que são os seguintes:

\begin{abstract}
Princípios e Diretrizes Nacionais para a gestão do trabalho no âmbito do SUAS. Princípios Éticos para os Trabalhadores da Assistência Social. Equipes de Referência. Diretrizes para a Política Nacional de Capacitação. Diretrizes Nacionais Para os Planos de Carreira, Cargos e Salários. Diretrizes para Entidades e Organizações de Assistência Social. Diretrizes para o cofinanciamento da Gestão do trabalho. Responsabilidades e Atribuições do Gestor Federal, dos Gestores Estaduais, do Gestor do Distrito Federal e dos Gestores Municipais para a Gestão do Trabalho no âmbito do SUAS.
\end{abstract}

\footnotetext{
${ }^{6} \mathrm{O}$ processo licitatório na região de Guarapuava também se dá para contratar profissionais para trabalhar nas diversas políticas públicas. Isso se dá da seguinte maneira: lança-se um edital, no qual constam as vagas de trabalho e a remuneração mínima e máxima. Isso é distribuído amplamente entre os profissionais candidatos. No dia estipulado, cada profissional chega com um envelope contendo o preço pela sua força de trabalho (exatamente como acontece com licitações de mercadorias). Aquele profissional que se aproximar mais do preço mínimo é quem vai assinar o contrato de trabalho por um ano, podendo ser renovado por mais um.
} 
Organização do Cadastro Nacional de Trabalhadores do SUAS - Módulo CADSUAS. Controle Social da Gestão do Trabalho no âmbito do SUAS. Regras de Transição (PARANÁ, 2006, p. 18).

Esses princípios dizem respeito à gestão do trabalho no âmbito das políticas sociais públicas, as quais são incorporadas pela Assistência Social e também pela Política de Recursos Humanos a fim de tornar as relações de trabalho mais dignas e também estáveis entre os trabalhadores e os usuários dos serviços. Desta maneira, a gestão do trabalho no SUAS garantiriam que os trabalhadores da área tenham Planos de Carreira, Cargos e Salários (PCCS). Isso significa um incentivo à formação continuada e também garantia de que os salários sejam definidos por nível de formação, possibilitando, por exemplo, que todos que tenham nível superior recebam o mesmo valor, não fazendo distinção de profissão. Isso é fundamental para a Política de Assistência Social, uma vez que:

\begin{abstract}
As possibilidades de atuação profissional não podem ser desvinculadas das condições e processos em que se realiza o trabalho. É nesse sentido que as competências e atribuições profissionais devem se inserir na perspectiva da gestão do trabalho em seu sentido mais amplo, que contemple ao menos três dimensões indissociáveis: as atividades exercidas pelos (as) trabalhadores (as), as condições materiais, institucionais, físicas e financeiras, e os meios e instrumentos necessários ao seu exercício. A garantia e articulação dessas dimensões são fundamentais para que os (as) trabalhadores (as) possam atuar na perspectiva de efetivar a política de Assistência Social e materializar o acesso da população aos direitos sociais (CONSELHO FEDERAL DE SERVIÇO SOCIAL, 2007, p. 43).
\end{abstract}

Outro aspecto importante que a NOB/RH-SUAS ressalta é a forma de se contratar o trabalhador (a) para seu serviço. A partir dela, esse contrato só seria possível por meio de concurso público, dado que este possibilita relações estáveis com os usuários. No que tange a gestão do trabalho no SUAS e para que haja a prestação de serviços com qualidade é necessário:

O estabelecimento de relações de trabalho estáveis, a garantia institucional e condições e meios necessários à realização das atividades são indispensáveis para o exercício profissional. Nessa perspectiva, o trabalho precarizado que se manifesta na ausência das dimensões anteriormente citadas, nos baixos salários, na elevada carga de trabalho, na alta rotatividade, na inexistência de possibilidades institucionais para atender às demandas dos (as) usuários (as), entre outros, é um obstáculo para a atuação profissional, para a universalização das políticas sociais, para as relações saudáveis entre trabalhadores (as) e 
usuários (as) e para a qualidade e continuidade dos programas, projetos e serviços (CONSELHO FEDERAL DE SERVIÇO SOCIAL, 2007, p. 43-44).

Para o CFESS (2007), a gestão do trabalho no SUAS, além de garantir maior qualidade na prestação de serviços, também colabora no enfrentamento das relações de trabalho precárias impostas pelo sistema capitalista de produção. Além do mais, é uma forma de garantir os direitos trabalhistas dos profissionais que têm como função também a garantia de direitos sociais.

É neste contexto que iremos, a seguir, mostrar as condições de trabalho dos Assistentes Sociais que desenvolvem suas atividades na Assistência Social na região de Guarapuava-PR. Os dados quantitativos mostraram que dos quinze sujeitos que aceitaram participar da pesquisa, quatorze são do sexo feminino, o que mostra a característica feminina que ainda existe na profissão (ESTEVÃO, 1999; CASTRO, 2003; SILVA E SILVA, 2007).

Quanto à instituição em que se formaram cinco fizeram sua graduação na Universidade Estadual do Centro-Oeste (UNICENTRO), cinco na Universidade Estadual de Ponta Grossa (UEPG); dois na Pontifícia Universidade Católica do Paraná (PUC-PR); um na Universidade do Contestado, um iniciou o curso na PUC-PR e terminou na UNICENTRO e um não respondeu. Vale ressaltar que todos cursaram Serviço Social presencial. Os dados são significativos quando apontam que a maioria dos profissionais consegue atuar na região das Universidades em que se formaram, considerando que dos quinze entrevistados apenas um iniciou a formação na Pontifícia Universidade Católica do Paraná (PUC/PR), mas concluiu na UNICENTRO. Os demais se formaram na UNICENTRO e na UEPG. Isto não significa que os cursos formam profissionais apenas para atender às demandas da região, mas que a região possui mercado de trabalho para estes, mesmo que precário. Os currículos dos cursos contêm dimensões da realidade regional que são trabalhadas no decorrer da formação, justamente para melhor preparar o futuro assistente social para sua inserção sociocupacional.

Quanto à instituição de atuação: dois trabalham no Centro de Referência Especializado de Assistência Social (CREAS); quatro no Órgão Gestor; cinco no Centro de Referência de Assistência Social (CRAS); três na Secretaria de Estado do Trabalho, Emprego e Promoção Social (SETP) e um no Órgão Gestor e Programa Pró-Egresso. Como 
se pode perceber o percentual de Assistentes Sociais que trabalham em mais de um espaço ocupacional é pequeno. Enquanto que os que trabalham nos CRAS e CREAS é maioria. Isso pode significar que a maioria dos campos de atuação são abertos por uma obrigatoriedade da lei (BRASIL, 2007), sendo que esta serve como aparato na ampliação dos espaços ocupacionais do Serviço Social na região. Percebe-se que toda a luta dos profissionais para a efetivação da legislação da Assistência Social não é em vão. É uma via de mão dupla: abrem-se espaços de trabalho para os profissionais que, por sua vez, irão ampliar a garantia do acesso aos direitos dos cidadãos. Podemos afirmar que a aprovação da NOB/SUAS-RH foi de fundamental importância para expansão dos campos ocupacionais para o Serviço Social na Política de Assistência Social. Porém, não significa que os campos mantêm as condições éticas e técnicas para o trabalho do profissional previstas na Resolução no 493 de agosto/ 2006 estabelecida pelos CFESS.

Os dados mostram que ainda é nítido o caráter feminino da profissão. Dos quinze entrevistados, apenas um é do sexo masculino.

Gráfico 1 - Divisão por Sexo

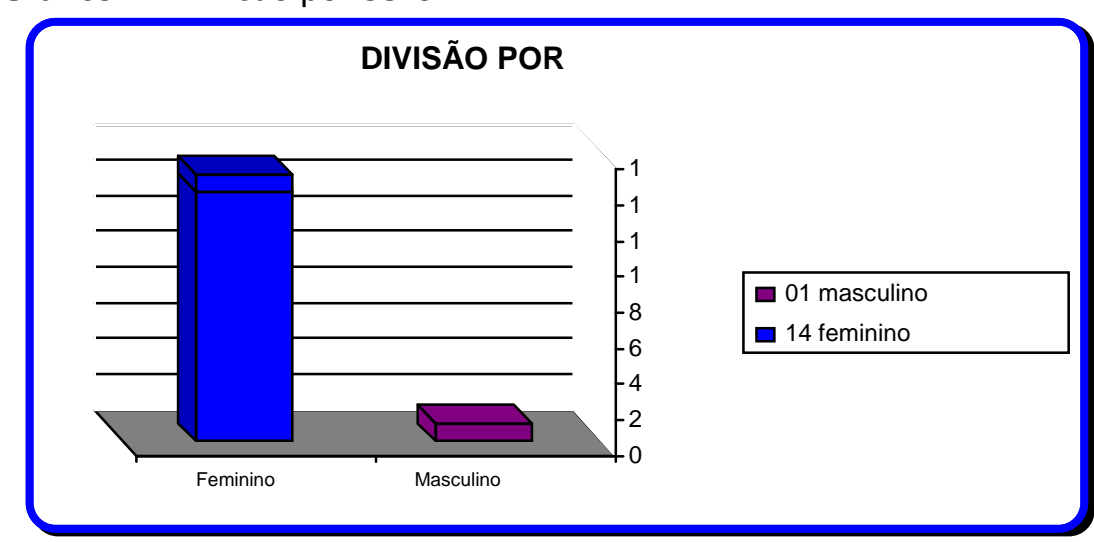

Fonte: Elaborado pela autora com base na coleta de dados da pesquisa realizada em 2010.

O Serviço Social teve em sua origem uma característica predominantemente feminina (ESTEVÃO, 1999). A Assistência Social quando era prestada pelas Organizações Não Governamentais (ONGs) das Igrejas, também tinha essa mesma característica (ESTEVÃO, 1999; MESTRINER, 2001). No entanto, de modo geral, isso mudou no Brasil, tanto que nos cursos de formação, de forma geral existe significativa presença masculina, assim como nos campos de atuação também. Entretanto, foi surpresa para a 
pesquisadora perceber que na região de Guarapuava o sexo feminino predomine nos espaços de atuação na Política de Assistência Social, porque na UNICENTRO existe um percentual em torno de 30\% de alunos do sexo masculino. Em meados de 2004, o CFESS realizou uma pesquisa do perfil dos assistentes sociais no Brasil e constatou que $97 \%$ são do sexo feminino, o que confirma a tendência histórica da profissão (CONSELHO FEDERAL DE SERVIÇO SOCIAL, 2005).

Quanto às condições do regime de trabalho, os dados mostraram que dez sujeitos trabalham sem Registro em Carteira; quatro com Registro em Carteira, e apenas um é estatutário.

Gráfico 2 - Registro em Carteira de Trabalho

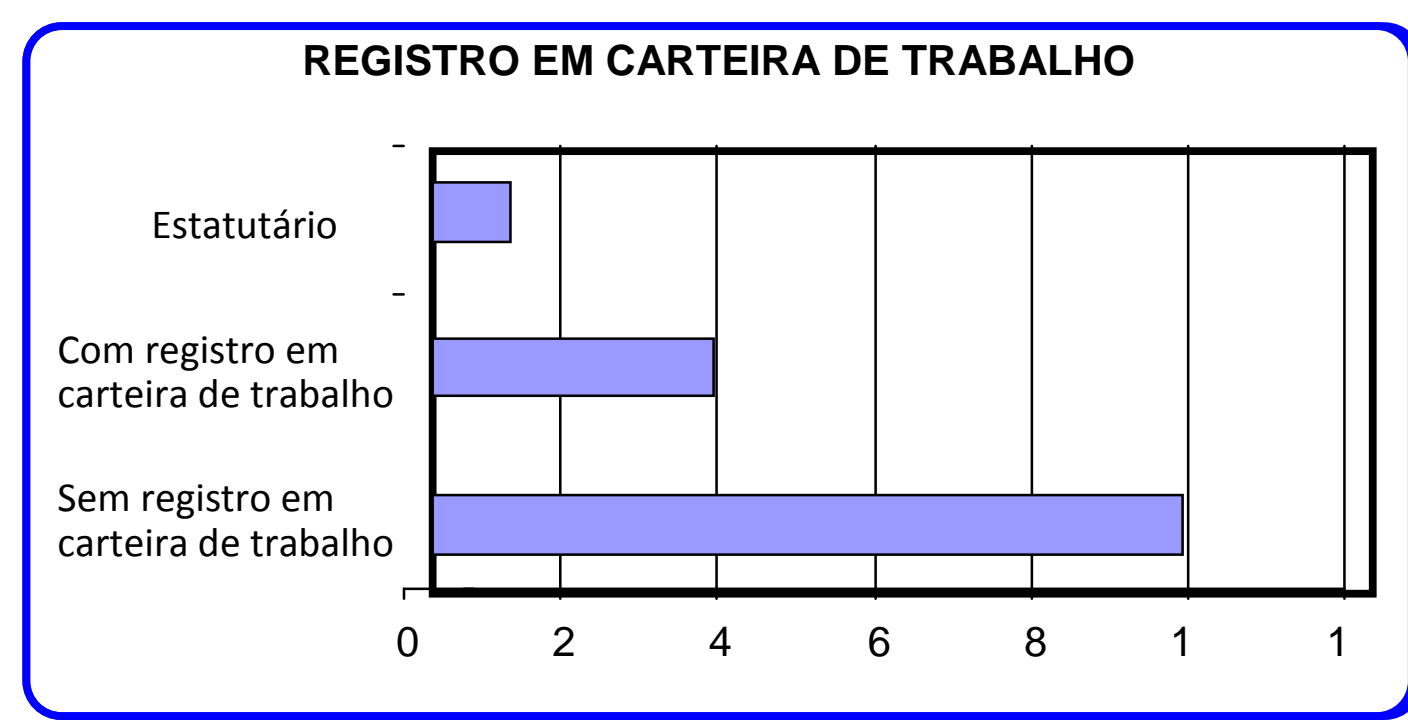

Fonte: Elaborado pela autora com base na coleta de dados da pesquisa realizada em 2010.

Quando o trabalhador é concursado o seu contrato de trabalho é estatutário, e não tem registro em carteira. Então, entre os dez que não têm registro estão tanto os contratados de forma irregular, que significam contratos temporários e precários que violam os direitos trabalhistas, quanto os estatutários.

Quando questionados sobre os tipos de contratos a que estão vinculados, três responderam ser por processo licitatório, um é cedido de outra Secretaria; três são cargos comissionados; cinco são concursados; dois têm contrato temporário e um encontra-se em desvio de função. Como vemos abaixo, apenas 33\% dos trabalhadores estão em condição estável de trabalho e podem prestar serviço continuado, por meio do qual 
podem construir processos de trabalho em suas instituições empregatícias a longo prazo. Vale ressaltar que os contratos temporários são fixados pelo prazo de um, e no máximo dois anos. Isso fragiliza a prestação de serviços continuados, pois cada vez que troca de profissional em determinado espaço de atuação, recomeça-se todo o processo de conhecimento da realidade e constituição de vínculos com os usuários.

Os demais possuem vínculos fragilizados. São condições de trabalho precárias, temporárias, flexibilizadas e que não dão segurança para o trabalhador e, consequentemente, não são relações seguras para os usuários que precisam desenvolver vínculos de confiança com os trabalhadores. Nesse tipo de relações de trabalho, os profissionais encontram dificuldades para construir processos de trabalho, pois a temporalidade e as condições precárias exigem respostas imediatas para demandas também imediatas.

Gráfico 3 - Tipo de Contrato de Trabalho dos Assistentes Sociais

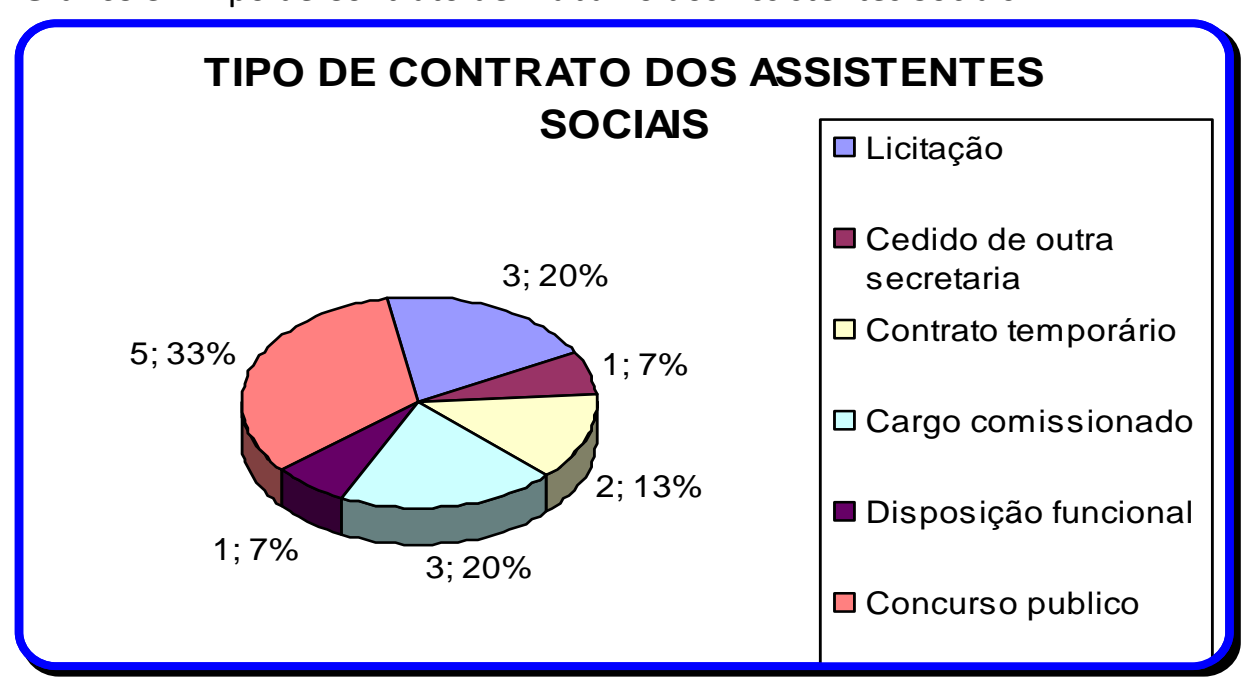

Fonte: Elaborado pela autora com base na coleta de dados da pesquisa realizada em 2010.

A NOB/SUAS-RH exige que para trabalhar na Política de Assistência Social os profissionais devem ser contratados via concurso público. Porém, os dados mostram que dez trabalhadores têm condições de trabalho precarizados, e apenas cinco estão de acordo com o que ela preconiza. Isso demonstra a fragilidade de efetivação da norma, e, consequentemente, da implementação do SUAS, pois os trabalhadores da área social tem direitos trabalhistas que precisam ser respeitados. 
Desses contratos, enfatizamos o seguinte: treze profissionais são contratados como Assistentes Sociais; um como Assessor de Serviço Social e apenas um ocupa o cargo de chefia, sendo chamado de Assistente Chefia.

Gráfico 4 - Especificação da Função dos Assistentes Sociais

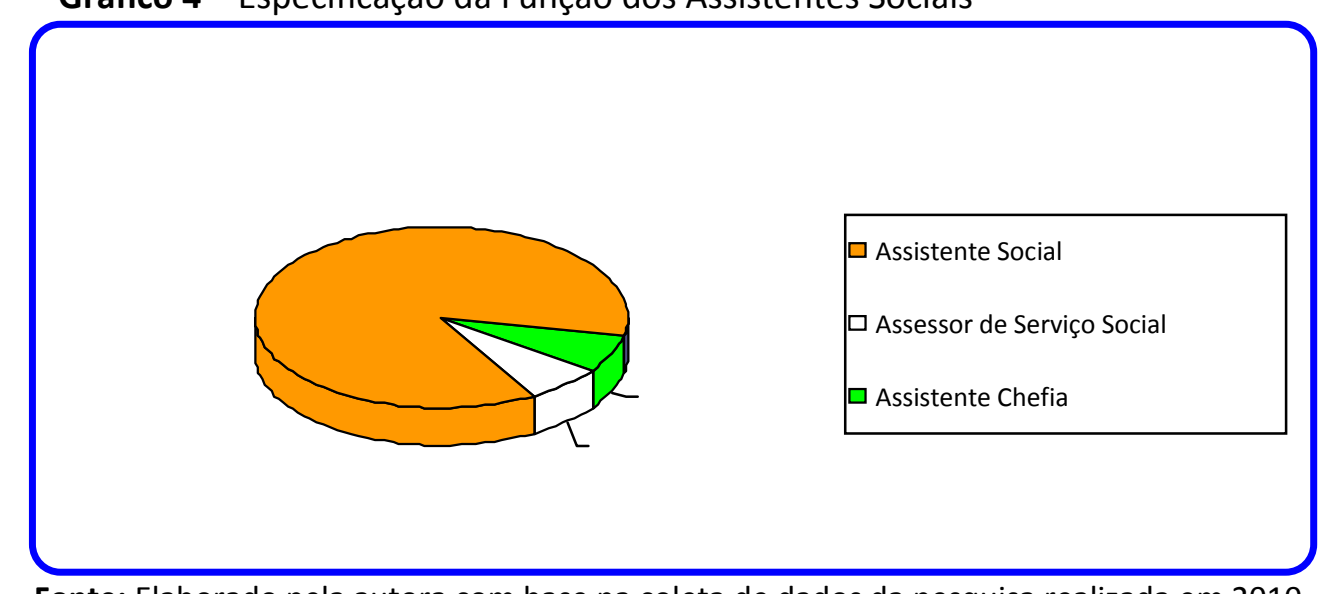

Fonte: Elaborado pela autora com base na coleta de dados da pesquisa realizada em 2010.

Desde o seu surgimento, o Serviço Social, por meio dos agentes profissionais, tem a função de executar as tarefas a ele destinadas pelos seus empregadores. Com o passar do tempo, em especial quando o Serviço Social começa a repensar a sua prática profissional, descobre-se a necessidade de planejar suas ações e passa a ser protagonista na construção de ações mediatas. Com isso, passa a ocupar espaços de planejamento e decisão sobre as políticas públicas. Agora, chama a atenção o fato de que os profissionais de Serviço Social, na sua maioria, ainda não ocupem cargos de gestão nos espaços ocupacionais da região investigada. Abreo et al. (1999) fala que o Serviço Social precisa ultrapassar a execução de tarefas terminais e ousar mais: assumir o planejamento das ações.

Esta realidade leva o Serviço Social a procurar novos rumos, ou seja, o Assistente Social tem que ultrapassar as tarefas terminais burocráticas trazendo para si maiores responsabilidades, através da criação e otimização de novas propostas de atuação que traga respostas concretas às demandas onde o Assistente Social deve ser um profissional propositor e não só executor (ABREO et al., 1999, p. 1).

Atualmente, o Serviço Social trabalha na gestão de políticas, e uma delas é a Política de Assistência Social, e não se trata de gestão apenas municipal, mas em outros 
níveis também de maior relevância, como estadual e federal. Isso dá um novo rosto para a profissão, revela a maioridade do Serviço Social passando de executor a gestor de programas e projetos sociais. Nesse aspecto, o planejamento é ferramenta fundamental uma vez que ele proporciona a possibilidade de construir intervenções mediatas nos espaços ocupacionais dentro das políticas. Outro aspecto importante é que dos quinze sujeitos, quatorze contribuem com o Instituto Nacional do Seguro Social (INSS), seja com desconto em folha ou autônomo e um não contribui, nem de forma estatutária e nem de forma autônoma.

A média salarial destes profissionais varia entre três a quatro salários mínimos (sete profissionais) e quatro a cinco salários mínimos (quatro profissionais). Os quatro restantes têm um salário inferior a três salários mínimos. ${ }^{7}$

Gráfico 5 - A Média Salarial dos Assistentes Sociais

\section{MÉDIA}

Mais de cinco salários

Quatro a cinco salários

Três a auatro salários

Dois a três salários

Um a dois salários

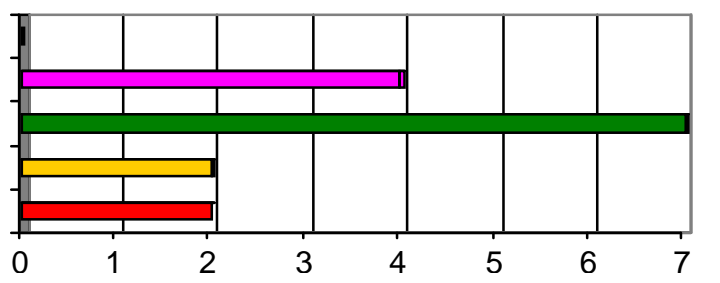

- Acima de $\mathrm{R} \$ 2.550,00$

$\square$ Entre $R \$ 1.530,00$ e $R \$ 2.040,00$

$\square$ Entre $R \$ 510,00$ e $R \$ 1.020,00$

口 Entre $R \$ 2.040,00$ e $R \$ 2.550,00$

$\square$ Entre $R \$ 1.020,00$ e $R \$ 1.530,00$

Fonte: Elaborado pela autora com base na coleta de dados da pesquisa realizada em 2010

Vale ressaltar que concretamente a profissão não possui um piso salarial. Portanto, os salários são definidos pela média regional, ou seja, os contratantes pesquisam o que estão pagando para os profissionais e assim o fazem. A carga horária de trabalho é de quarenta horas ${ }^{8}$ semanais para quatorze dos participantes, e um omitiu essa informação.

No que diz respeito ao tempo de serviço e atuação desses profissionais na política de Assistência Social, apuramos, por meio da pesquisa, que os profissionais têm tempo de

\footnotetext{
${ }^{7}$ Quando a pesquisa foi realizada o salário mínimo era de $\mathrm{R} \$ 510,00$.

${ }^{8}$ Vale ressaltar que as 30 horas de trabalho do assistente social estava na pauta de lutas da época e que posteriormente foi oficializada por meio da aprovação da Lei 12.317, em 26 de agosto de 2010.
} 
serviço entre um a quinze anos, compondo o seguinte panorama: quatro estão atuando na política de Assistência há menos de um ano; três atuam entre um a cinco anos; três já atuam entre cinco a dez anos; três atuam entre dez a quinze anos; e quatro pessoas não responderam. Isso mostra que a maioria dos Assistentes Sociais têm menos de cinco anos de experiência profissional. Essa inserção de profissionais com pouca experiência mostra a ampliação dos espaços ocupacionais para o Serviço Social, o que pode estar relacionado a implementação do SUAS na região.

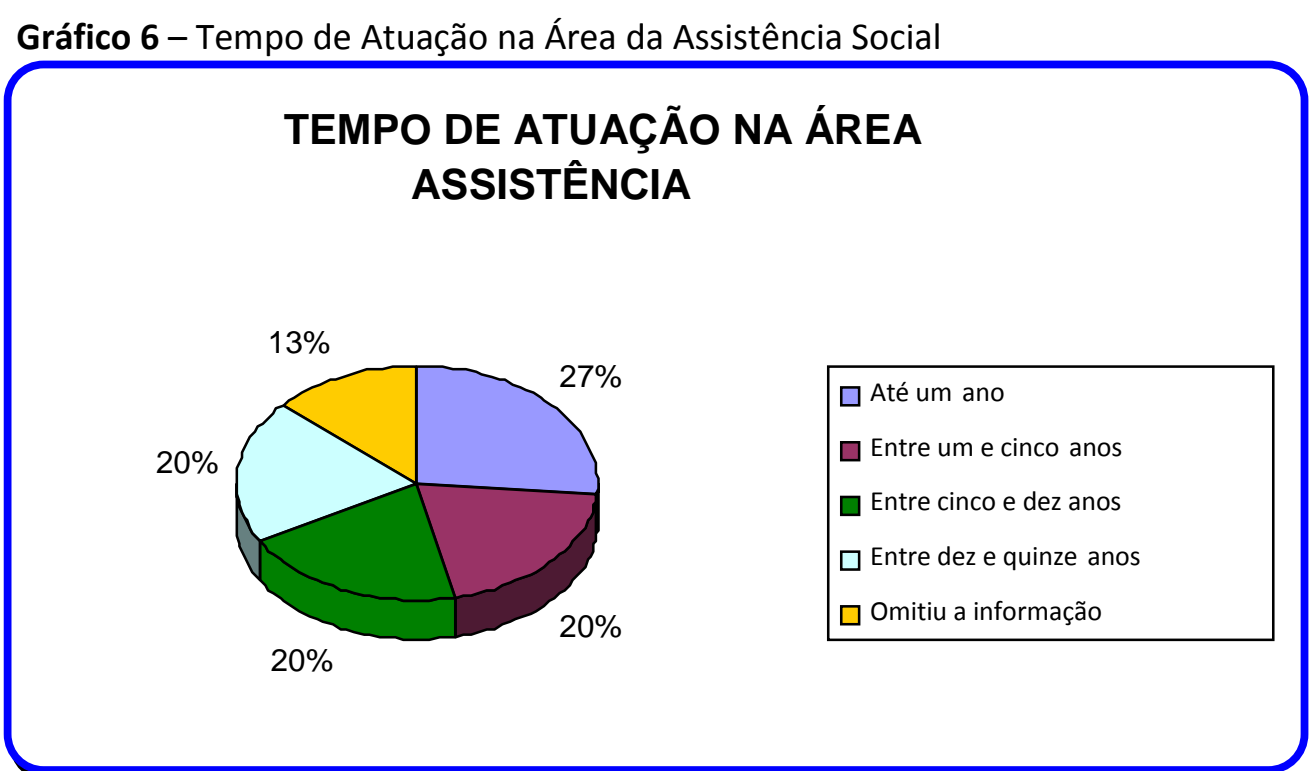

Fonte: Elaborado pela autora com base na coleta de dados da pesquisa realizada em 2010.

Destes profissionais, apenas um trabalha em duas instituições diferentes. Se quatorze deles tem uma carga horária de quarenta horas, e um não respondeu, pode significar que esse é um que tem dupla jornada ou um deles tem mais que quarenta horas de trabalho.

E a questão aberta apontou algumas categorias interessantes para a compreensão de como trabalham os Assistentes Sociais na Política de Assistência Social, pois por meio delas percebeu-se que as condições de trabalho do Assistente Social estão fragilizadas devido às contratações e salários precários, sobrecarga de trabalho, pouco suporte na estrutura física e recursos para o desenvolvimento da intervenção no cotidiano das instituições. 
O Conselho Federal de Serviço Social (CFESS) publicou a Resolução no 493 do CFESS em 2006 que trata das condições éticas e técnicas do exercício profissional do assistente social em qualquer espaço ocupacional. Quanto aos locais de trabalho o CFESS propõe que

[...] deve ser dotado de espaço suficiente, para abordagens individuais ou coletivas, conforme as características dos serviços prestados, e deve possuir e garantir as seguintes características físicas: a) iluminação adequada ao trabalho diurno e noturno, conforme a organização institucional; b) recursos que garantam a privacidade do usuário naquilo que for revelado durante o processo de intervenção profissional; c) ventilação adequada a atendimentos breves ou demorados e com portas fechadas d) espaço adequado para colocação de arquivos para a adequada guarda de material técnico de caráter reservado (CONSELHO FEDERAL DE SERVIÇO SOCIAL, 2006).

Os contratantes precisam garantir espaços suficientes, adequados e materiais necessários para o trabalho do profissional, uma vez que não significa apenas conforto, mas um atendimento ético profissional do usuário. Tendo condições favoráveis, o assistente social consegue, além de atender individualmente os sujeitos que o procuram, também guardar sigilosamente os documentos que the dizem respeito. A ética profissional além de ser obrigatoriedade do assistente social é também um direito respaldado no Código de Ética que afirma que "[...] constituem-se direitos do Assistente Social a $[\ldots]$ d) inviolabilidade do local de trabalho e respectivos arquivos e documentação, garantindo o sigilo profissional" (CONSELHO FEDERAL DE SERVIÇO SOCIAL, 1993b). Assim como "[...] a) dispor de condições de trabalho condignas, seja em entidades públicas ou privadas, de forma a garantir a qualidade do exercício profissional" (CONSELHO FEDERAL DE SERVIÇO SOCIAL, 1993b).

Outro aspecto importante é a realidade de favoritismo e barganha de votos, ainda muito presente, que se constitui como desafio para a prática profissional. Essa prática é histórica ${ }^{9}$ no Brasil e o Serviço Social convive com ela desde a sua origem. No entanto, isso tem se constituído um vasto campo de desafios para os assistentes sociais, uma vez que lutam pela ampliação dos serviços prestados aos usuários numa perspectiva de direito e não de favor.

\footnotetext{
${ }^{9}$ Alayón (1992); Costa (2006); Couto (2008); Faoro (1979); Leal (1997); Martins (1994); Mestriner (2001).
} 


\section{Considerações finais}

O objetivo deste trabalho foi discutir as condições de trabalho dos Assistentes Sociais na região de Guarapuava-PR. Para isso, examinamos a categoria de trabalho e suas metamorfoses a partir do processo de amadurecimento do sistema capitalista. As consequências de tal processo são sentidas pela classe trabalhadora na qual o Serviço Social se inclui. Pensar as condições de trabalho dos assistentes sociais é discussão recente na Política de Assistência Social e pudemos perceber que a implementação de uma política da gestão do trabalho, como propõe a NOB/SUAS-RH, ainda está em fase embrionária.

O resultado da pesquisa mostrou que a maioria dos Assistentes Sociais são do sexo feminino, o que nos remonta as origens tanto da profissão quando da Assistência Social. Isso desperta a atenção, pois nos cursos de formação profissional ${ }^{10}$ já existe um número significativo de pessoas do sexo masculino formadas.

Percebemos a fragilidade dos vínculos de trabalho dos profissionais, e essa fragilidade repercute diretamente na prestação de serviços públicos que é direito dos usuários. São contratos precários, temporários e flexibilizados que não dão segurança aos profissionais, tampouco aos usuários dos serviços por eles prestados. Quando os contratos são temporários, os profissionais prestam serviços por um ou no máximo dois anos. Terminado o contrato, é feita a troca de profissionais e se começa novamente o processo de conhecimento da realidade por parte dos iniciantes, assim como, o processo de constituição de vínculos desses profissionais com os usuários, elemento importante para o desenvolvimento das potencialidades destes.

O Serviço Social, apesar de teoricamente ter se emancipado da execução de tarefas terminais e rotineiras, na região de Guarapuava ainda não está na função de coordenação de ações, mas como executor. O profissional possui sobrecarga de trabalho na execução de serviços, muitas vezes imediato, pois as demandas são muitas e imediatas e como tais requerem uma resposta profissional também imediata. Talvez isso esteja associado às instituições contratantes que querem os assistentes sociais apenas para executar serviços emergenciais, ou a categoria que ainda não venceu o desafio de conquistar os espaços de

\footnotetext{
${ }^{10}$ Estamos nos referindo ao curso de Serviço Social da Universidade Estadual do Centro-Oeste (UNICENTRO) e da Faculdade Guairacá, ambos com sede em Guarapuava-PR.
} 
coordenação. Vale a reflexão. Esses espaços poderiam ajudar a profissão a vencer os históricos resquícios conservadores, quando os profissionais apenas eram meros executores de tarefas, tornando-se propositores de ações efetivas na garantia dos direitos sociais. Isso requer que as instituições contratantes alarguem sua compreensão e percebam que os profissionais de Serviço Social têm formação suficiente para empreender a coordenação de políticas sociais. A par disso, faz-se necessário que, tanto contratantes quanto profissionais, compreendam que a função social do profissional de Serviço Social não se limita apenas a execução dos serviços, mas também elaboração, o planejamento e a avaliação dos serviços e das políticas públicas.

Praticamente a metade dos Assistentes Sociais têm remuneração entre três a quatro salários mínimos, o que corresponde a um montante entre $R \$ 1.530,00$ e $R \$$ $2.040,00$. Ninguém recebe salário superior a $R \$ 2 \cdot 800,00$. A remuneração é variada, pois a profissão não possui um piso salarial. E, além disso, como a maioria trabalha em condições de contratos vulnerabilizadas, os contratantes instituem o salário. Isso desafia a categoria a lutar por um piso salarial.

Por meio desta pesquisa, foi possível perceber alguns desafios que a categoria precisa vencer, tais como: a efetivação da NOB/SUAS-RH, a instituição de um piso salarial, a luta por concurso público dentro das normas legais e o cumprimento das Resoluções do Conselho Federal de Serviço Social (CFESS) que requerem das instituições espaços adequados para a profissão desenvolver suas intervenções.

\section{Referências}

ABREO, A. C. S. B. et al. Os impactos das dimensões societárias contemporâneas e o perfil do assistente social. Serviço Social em Revista, Londrina, v.1, n. 2, jan./jun. 1999.

ALAYÓN, N. Assistência e assistencialismo: controle dos pobres ou erradicação da pobreza? São Paulo: Cortez, 1992.

ALBORNOZ, S. O que é o trabalho. 6. ed. São Paulo: Brasiliense, 1994.

ANTUNES, R. Adeus ao trabalho? ensaio sobre as metamorfoses e a centralidade do mundo do trabalho. 7. ed. São Paulo: Cortez, 2000.

BOURGUIGNON, J. A. O processo da pesquisa e suas implicações teórico-metodológicas e sociais. Emancipação, Ponta Grossa, v. 1, n. 1, 2001. 
CASTRO, M. M. História do serviço social na América Latina. 6. ed. São Paulo: Cortez, 2003.

CONSELHO FEDERAL DE SERVIÇO SOCIAL. Lei no 8.662. Lei de Regulamentação da Profissão de Serviço Social. Brasília, 1993a.

. Código de Ética do Assistente Social. Resolução no 273 de 13 de março de 1993. 1993b.

(Org.). Assistentes sociais no Brasil: elementos para o estudo do perfil profissional. Brasília, 2005.

. Resolução $n$ o 493/06. Dispõe sobre as condições éticas e técnicas do exercício profissional do assistente social. Brasília, 2006.

. Parâmetro para atuação de assistentes sociais e psicólogos (as) na Política de Assistência Social. Brasília, CFP/CFESS, 2007.

CHIZZOTTI, Antonio. Pesquisa em ciências humanas e sociais. 3. ed. São Paulo: Cortez, 1998.

COLMÁN, E.; POLA, K. D. Trabalho em Marx e serviço social. Serviço Social, Londrina, v. 12, n. 1, jul./dez. 2009.

COSTA, L. C. Os impasses do Estado no Brasil. Ponta Grossa: UEPG, 2006.

COUTO, B. R. O direito social e a assistência social na sociedade brasileira: uma equação possível? 3. ed. São Paulo: Cortez, 2008.

ESTEVÃO, A. M. R. O que é serviço social. 6. ed. São Paulo: Brasiliense, 1999.

FALEIROS, V. P. Saber profissional e poder institucional. 9. ed. São Paulo: Cortez, 2009.

FAORO, R. Os donos do poder: formação do patronato político brasileiro. 5. ed. Porto Alegre: Globo, 1979. v. 1/2.

IAMAMOTO, M. V.; CARVALHO, R. Relações sociais e serviço social no Brasil. São Paulo: Cortez, 1982.

. O serviço social na contemporaneidade: trabalho e formação profissional. 9. ed.

São Paulo, Cortez, 2005.

LEAL, V. N. Coronelismo, enxada e voto: o município e o regime representativo no Brasil. 3. ed. Rio de Janeiro: Editora Nova Fronteira, 1997.

LESSA, S. O processo de produção/reprodução social: trabalho e sociabilidade. In: CONSELHO FEDERAL DE SERVIÇO SOCIAL; ASSOCIAÇÃO BRASILEIRA DE ENSINO E PESQUISA EM SERVIÇO SOCIAL. Capacitação em Serviço Social e política social. Brasília: CEAD, 1999. Módulo 2, p. 1933. 
. Introdução à filosofia de Marx. São Paulo: Expressão Popular, 2008.

MARTINS, J. S. O poder do atraso: ensaios de Sociologia da História Lenta. São Paulo: HUCITEC, 1994.

MARX, K. O capital. Rio de Janeiro: Civilização Brasileira, 1971. v. 1. n. 1.

MESTRINER, M. L. O Estado entre a filantropia e a assistência social. 2. ed. São Paulo: Cortez, 2001.

NETTO, J. P. Transformações societárias e serviço social: notas para uma análise prospectiva da profissão no Brasil. Revista Serviço Social \& Sociedade, São Paulo, Ano 17, n. 50, abr. 1996.

BRASIL. República Federativa do Brasil. Norma Operacional Básica de Recursos Humanos. Brasília, 2007.

SILVA E SILVA, M. O. O serviço social e o popular: resgate teórico-metodológico do projeto profissional de ruptura. 4. ed. São Paulo: Cortez, 2007.

SOUZA, R. B.; AZEVEDO, V. G. O assistente social e a ação competente. Revista Serviço Social \& Sociedade, São Paulo, Ano 25, n. 80, nov. 2004.

PARANÁ. Sistema Único de Assistência Social. Sistema Municipal e Gestão Local do CRAS Curitiba, 2006. Caderno I e II.

TAVARES, M. A. Acumulação, trabalho e desigualdades sociais. In: CONSELHO FEDERAL DE SERVIÇO SOCIAL. SERVIÇO SOCIAL - CFESS. Direitos sociais e competências profissionais. Brasília: CFESS/ABEPSS, 2009.

Recebido em: 27/03/2012

Aprovado em: 10/06/2012 